\title{
Application of Solar Energy for Recovery of Water from Atmospheric Air in Climatic Zones of Saudi Arabia
}

\author{
Ahmed M. Hamed ${ }^{1,3}$, Ayman A. Aly ${ }^{1,2}$, El-Shafei B. Zeidan ${ }^{1,3}$ \\ ${ }^{1}$ Department of Mechanical Engineering, Faculty of Engineering, Taif University, Taif, KSA; ${ }^{2}$ Department of Mechanical Engineer- \\ ing, Faculty of Engineering, Assiut University, Assiut, Egypt; ${ }^{3}$ Department of Mechanical Power Engineering, Faculty of Engineer- \\ ing, Mansoura University, Mansoura, Egypt. \\ E-mail: amhamed@mans.edu.eg, \{ayman_aly,ezeidan2002\}@yahoo.com
}

Received December $8^{\text {th }}, 2010$; revised January $18^{\text {th }}, 2011$; accepted January $25^{\text {th }}, 2011$.

\begin{abstract}
In the present work, an investigation on the application of solar energy to heat a sandy bed impregnated with calcium chloride for recovery of water from atmospheric air is presented. The study also aimed at evaluating the effects of different parameters on the productivity of the system during regeneration. These parameters include system design characteristics and the climatic conditions. An experimental unit has been designed and installed for this purpose in climatic conditions of Taif area, Saudi Arabia. The experimental unit which has a surface area of $0.5 \mathrm{~m}^{2}$, comprises a solar/desiccant collector unit containing sandy bed impregnated with calcium chloride. The sandy layer impregnated with desiccant is subjected to ambient atmosphere to absorb water vapor in the night. During the sunshine period, the layer is covered with glass layer where desiccant is regenerated and water vapor is condensed on the glass surface. Ambient temperature, bed temperature and temperature of glass surface are recorded. Also, the productivity of the system has been evaluated. Desiccant concentration at start of regeneration is selected on the basis of the climatic data of Al-Hada region, which is located at Taif area, Saudi Arabia. Experimental measurements show that about 1.0 liter per $\mathrm{m}^{2}$ of pure water can be regenerated from the desiccant bed at the climatic conditions of Taif. Liquid desiccant with initial concentration of $30 \%$ can be regenerated to a final concentration of about $44 \%$. Desiccant concentration at start of regeneration is selected on the basis of the climatic data of Al-Hada region. The climate of Taif city is dry compared with that for Al-Hada region. This method for extracting water from atmospheric air is more suitable for Al-Hada region especially in the fall and winter.
\end{abstract}

Keywords: Extraction, Atmospheric Air, Absorption, Liquid Desiccant, Solar Energy, Dew Collection, Regeneration

\section{Introduction}

Shortage of drinking water is chronic, severe, and widespread in the regions of Northern Africa, Middle East, and Central and Southern Asia. The problem of providing arid areas with fresh water can be solved by the following methods [1]:

- transportation of water from other locations;

- desalination of saline water (ground and underground);

- extraction of water from atmospheric air.

Transportation of water through these regions is usually very expensive, and desalination depends on the presence of saline water resources, which are usually rare in arid regions. Atmospheric air is a huge and renewable reservoir of water. This endless source of water is avail- able everywhere on the earth surface. The amount of water in atmospheric air is evaluated as $14000 \mathrm{~km}^{3}$, whereas the amount of fresh water in rivers and lakes on the earth surface is only about $1200 \mathrm{~km}^{3}$ [2]. The extraction of water from atmospheric air has several advantages compared with the other methods. The extraction of water from atmospheric air can be accomplished by different methods, the most common of these methods are cooling moist air to a temperature lower than the air dew point, and absorbing water vapor from moist air using a solid or a liquid desiccant, with subsequent recovery of the extracted water by heating the desiccant and condensing the evaporated water.

Choice of methods is an engineering decision dependent on local climatic conditions and economic fac- 
tors such as capital, operating, and energy costs. On the other hand, patented devices vary in scale and potable water output from small units suitable for one person's daily needs to structures as large as multi-story office buildings capable of supplying drinking water to an urban neighborhood.

\section{Water Resources and Usage in Saudi Arabia}

Saudi Arabia is about 2.15 million $\mathrm{km}^{2}$ of mostly desert area with long coasts along the Gulf (eastern border) and the Red Sea (western border). Along the Red Sea the western highlands rise up to 2000 meter above sea level and the land slopes gently towards the east. Water resources in Saudi Arabia include surface, underground, desalinated, and treated wastewater. There are neither lakes nor rivers in the entire country. The climate of Saudi Arabia is an arid one mostly characterized by hot and dry summer with cool and slightly wet winter with limited renewable water resources. The average annual rainfall is less than $150 \mathrm{~mm}$ in most of the country with the southwestern region of Saudi Arabia (about $10 \%$ of the total area of the country) has the highest average annual amount of rainfall (about $60 \%$ ). The groundwater is the main source of water in Saudi Arabia satisfying more than $90 \%$ of its water demand. Groundwater is stored in several aquifers over Saudi Arabia with quality varying between sites and aquifers. The total groundwater reserve in Saudi Arabia to a depth of three hundred meters below ground surface is estimated to be 2260 billion $\mathrm{m}^{3}$. The renewable groundwater resources are mainly stored in shallow alluvial aquifers and in basalt layers of varying thickness and width, which are found mostly in the southwest. These aquifers store about 84 billion cubic meters with an average annual recharge of 1196 million cubic meters $[3,4]$. Most of the fresh water used in Saudi Arabia (90\%) goes to agricultural use.

There are more than 200 dams, mostly located in the southwestern region, with storage capacity of about 830 million cubic meters for ground water recharge and flood control. There are major 30 distillation plants along the Red Sea and the Gulf and a pipeline system of more than $3700 \mathrm{~km}$ to transport water to remote areas. The approximate capacity of water production is about 1050 million cubic meters by 2000 . Distilled water is the main source of domestic demand. Considered one of the highest in the world, the annual national water demand in Saudi Arabia has increased from 2350 million cubic meters in 1980 to more than 27200 million cubic meters and the country is expected to face extreme water shortages [5].

Application of solar energy for extraction of water from atmospheric air in the climatic zones of Saudi Arabia is interesting when the transportation of potable water is expensive. In the following sections of the present study, systems and technologies for extraction of water from air are reviewed. Afterward, one these technologies will be selected for investigation in the present study in the climatic conditions of the city of Taif and Al-Hada region, Saudi Arabia.

\section{Literature Review of Systems and Technologies for Extracting Water from Air}

One of the first works dealing with water extraction from atmospheric air was published in Russia [6]. An apparatus consisting of a system of vertical and inclined channels in the earth to collect water from atmospheric air by cooling moist air to a temperature lower than its dew point has been proposed. The earth-water collector was proposed by Kobayashi [7].

Description and analysis of the theoretical cycle for absorption of water vapor from air with subsequent regeneration, by heating is presented in [1]. A theoretical limit for the maximum possible amount of water which can be collected from air using the desiccant through the absorption regeneration cycle at certain operating conditions of ambient parameters, heat to be added to the desiccant during regeneration and maximum available heating temperature could be evaluated through the analysis of this cycle. The absorption regeneration cycle, which can be applied for the production of water from atmospheric air, is shown in Figure 1. The theoretical cycle is plotted on the vapor pressure-concentration diagram for the operating absorbent and consists of four thermal processes which are:

- Process 1-2: isothermal absorption of water vapor from air.

- Process 2-3: constant concentration heating of the absorbent.

- Process 3-4: constant pressure regeneration of absorbent.

- Process 4-1: constant concentration cooling of absorbent.

This cycle can be applied in desiccant systems with different configurations and different heat sources. As the purpose of this cycle is to produce water from air and the input energy to the system is the heat added during the regeneration process, then the efficiency of the cycle can be defined as the ratio of heat added to regenerated vapor to the total heat added.

Theoretical analysis showed that, strong and weak solution concentration limits play a decisive role in the value of cycle efficiency. However, a modified cycle is described and analyzed by Sultan [9]. In this modified cycle, the practical considerations were taken into 


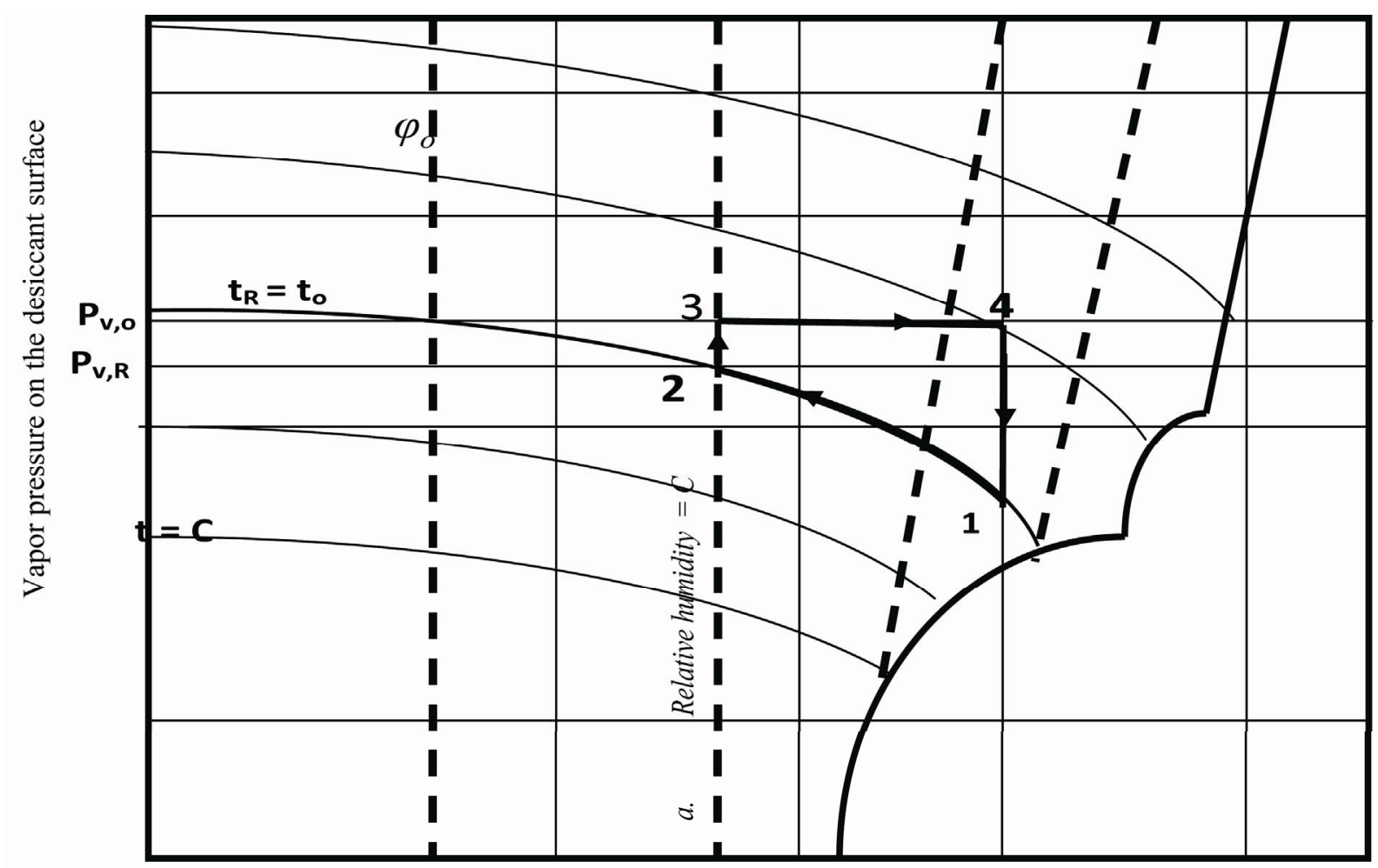

Figure 1. Absorption-regeneration cycle [1].

account.

Hall proposed a system for the production of water from atmospheric air by absorption using ethylene glycol as a liquid desiccant with subsequent recovery in a solar still [10]. The effects of temperature and humidity on the recovered water were studied and the results presented in the form of a composition-psychometric chart, but the paper does not provide any information about the mass of recovered water. Sofrata constructed a non-conventional system to collect water from air based on an adsorption-desorption process using a solid desiccant [11]. The study also discussed the feasibility of the application of air conditioning systems for collecting water from moist air by cooling it to a temperature lower than the dew point. Alayli used a typical S-shaped composite material for absorption of moisture from atmospheric air with subsequent regeneration using solar energy [12]. Hamed tested two methods to extract water from atmospheric air using solar energy [13]. The first method was based on cooling moist air to a temperature lower than the air dew point using solar absorption cooling system. The second method was based on the absorption of moisture from atmospheric air during the night using calcium chloride solution as a liquid desiccant, with subsequent recovery of absorbed water during the day. As a result of this study, the second method was recommended as a most suitable application of solar energy for water recovery from air. Abualhamayel, and Gandhidasan proposed the system shown in Figure 2 for water recovery from air [14]. The system consists of a flat, blackened, tilted surface and is covered by a single glazing with an air gap of about $45 \mathrm{~cm}$. The bottom of the unit is well insulated. At night, the strong absorbent flows down as a thin film over the glass cover in contact with the ambient air. If the vapor pressure of the strong desiccant is less than the vapor pressure of water in the atmospheric air, mass transfer takes place from the atmosphere to the absorbent. Due to absorption of moisture from the ambient air during the night, the absorbent becomes diluted. The water-rich absorbent must be heated during the day to recover the water from the weak absorbent. Therefore, during the day, the weak desiccant flows down as a thin film over the absorber surface. The weak absorbent is heated by solar energy, and the water that evaporates from the solution rises to the glass cover by convection where it is condensed on the underside of the glass cover and the absorbent leaving the unit becomes strong. The performance of the unit at night depends on the potential for mass transfer, which is the difference in water vapor pressure between the ambient air and desiccant.

The performance of a desiccant/collector system with a thick corrugated layer of blackened cloth to absorb water vapor at night from atmospheric air with subse- 


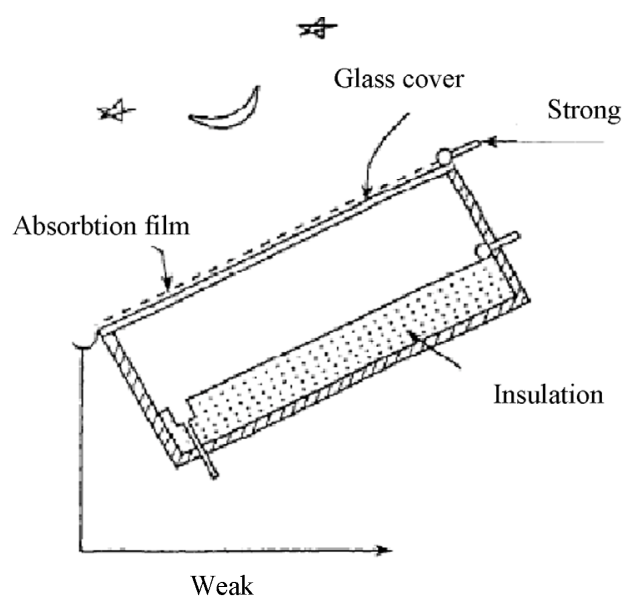

Night-time

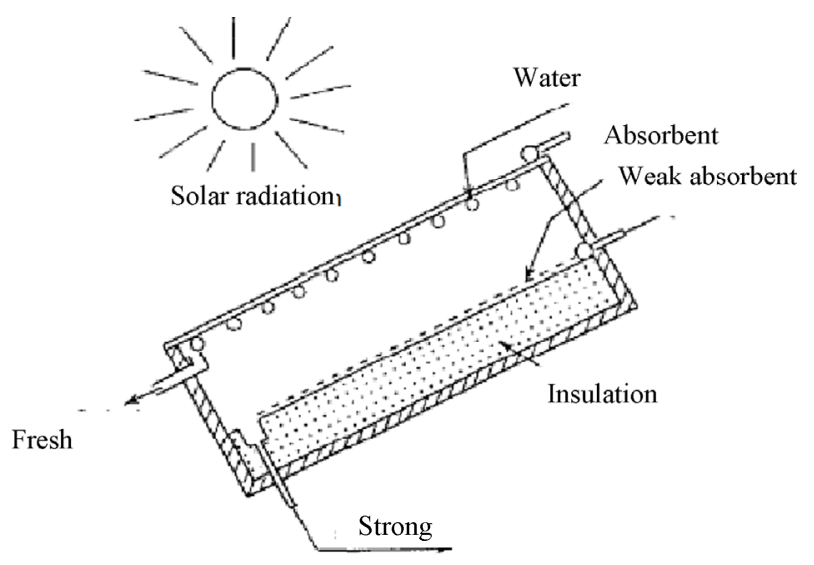

Day-time

Figure 2. The system proposed by Abualhamayel, and Gandhidasan [14].

quent regeneration during the day, using solar energy, was reported by Gad et al. [15]. Figure 3 shows a schematic diagram of the experimental apparatus. It consists mainly of three parts: a flat plate collector with a movable glass cover, a corrugated bed and an air-cooled condenser consisting of two parallel flat plates. Actual recorded results show that the solar operated system can provide about $1.5 \mathrm{l}$ of fresh water per square meter per day.

The need for economical realization of solar-desiccant systems for water production in arid areas is of great importance. Moreover, the inconvenience and relatively high cost of the desiccant bed limits the utilization of such units in large scale. In desert regions, mixing a sandy layer of the ground surface with desiccant is a promising method to minimize the cost of the vapor absorption bed was proposed [16]. The sandy layer impregnated with desiccant is subjected to ambient atmosphere to absorb water vapor in the night. During the sunshine period, the layer is covered with a greenhouse where desiccant is regenerated and water vapor is condensed on the transparent surface of the greenhouse or any other cold surface. Prediction of the absorption cycle performance requires knowledge of the percentage approach to saturation. In view of the design parameters of the absorption bed, the desiccant to sand mass ratio is an important factor affecting the rate of absorption and consequently the rate of water production. This issue is investigated experimentally in [16]. Extracting water from air by using sandy bed solar collector system is explored by Kabeel [17]. The system is studied theoretically and experimentally to evaluate the performance of the sandy bed impregnated with $30 \%$ concentration calcium chloride to produce water from moist air. It is reported that the system can provide up to about $1.2 l$ fresh water per square meter of glass cover per day in the climatic conditions of Tanta city, Egypt which is mostly humid.

The application of solar concentrator for fresh water production from the atmospheric air is reported in [18]. The results obtained in the AQUASOLIS project are used for assessing the use of solar trough concentration plants for applications other than heating and cooling, in particular for the production of fresh water for human consumption and for agriculture for Mediterranean countries. An apparatus for extracting moisture from the ambient air that includes application of a desiccant pond for absorbing moisture from air to produce a water rich desiccant has been presented in [19]. Atmospheric vapor is absorbed in the absorber section and the weak desiccant is circulated to the generator for heating and vapor condensation.

The capability of the glass pyramid shape with a multi-shelf solar system to extract water from humid air is explored in [20]. Two pyramids were used with different types of beds on the shelves. The beds are saturated with $30 \%$ concentrated calcium chloride solution. The pyramid sides were opened at night to allow the bed saturated with moist air and closed during the day to extract the moisture from the bed by solar radiation. The bed in the first pyramid was made of saw wood while it is made of cloth in the second pyramid with the same dimensions. The system was experimentally investigated at different climatic conditions to study the effect of pyramid shape on the absorption and regeneration processes. Preliminary results have shown that the cloths bed absorbs more solution $(9 \mathrm{~kg})$ as compared to the saw wood bed $(8 \mathrm{~kg})$. Adopting this approach, the system produces about 2.5 $l /\left(\right.$ day $\left.\mathrm{m}^{2}\right)$.

Selective water sorbents developed at the Boreskov Institute of Catalysis (Novosibirsk, Russia) for fresh water 

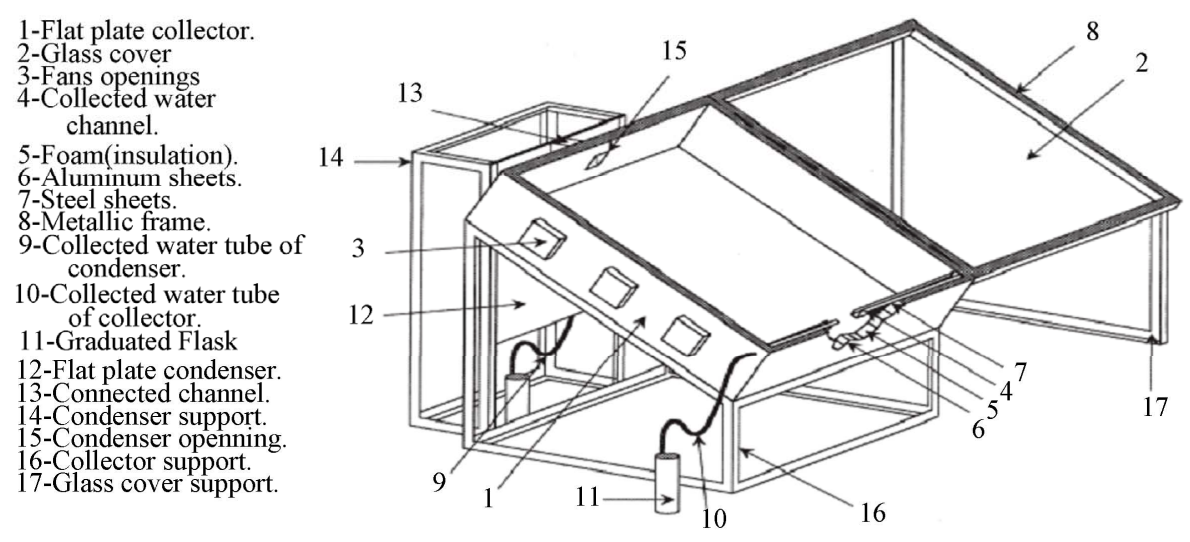

Figure 3. Schematic diagram of the experimental solar -desiccant collector for water recovery from air [15].

production from the atmosphere are reported by Aristov et al. [21]. The results of their lab-scale tests have demonstrated a feasibility of fresh water production with an output of 3-5 tones of water per 10 tones of the dry sorbent per day. Also, selective composite adsorbent for solar-driven fresh water production from atmospheric air is presented in [22]. It is synthesized by a patented ultra-large pore crystalline material MCM-41 as host matrices and calcium chloride as a hygroscopic salt. Adsorption capacity of the new composites is as high as $1.75 \mathrm{~kg} / \mathrm{kg}$ dry adsorbent, which is higher than composites synthesized by silica-gel and calcium chloride, and the adsorption rate of the new composites is also found attractive. A solar-driven water production test unit using the new adsorbent is also presented and tested. The experimental tests of this developed unit demonstrated a feasibility of fresh water production with daily water productivity more than $1.2 \mathrm{~kg} / \mathrm{m}^{2}$ of the solar collector area. The production of water from air on a continuous, 24-hour basis using more compact adsorption units by applying forced convection adsorption in packed porous bed is proposed in [23].

Water can be collected from air by direct cooling to a temperature lower than the dew point. A typical study was conducted analytically for the climatic conditions of UAE coastal regions [24]. It was reported that the quantity of fresh water obtained, by cooling method, depends on the properties of humid air, air velocity, cooling coil surface area, and the heat exchange arrangement. It is to be noted that this system uses chlorinated fluorocarbon compounds (CFCs) identified as contributors to the depletion of the ozone layer. For typical hot humid weather (Jeddah, Saudi Arabia, $21^{\circ} 23^{\circ} \mathrm{N}$ and $39^{\circ} \mathrm{E}$ ), Habeebullah reported that the daily variation of water yield showed to follow the relative humidity pattern with minimum during midday hours [25].

In the present work, it is aimed to investigate the performance of a solar powered desiccant/collector system at the climatic conditions of Taif area, Saudi Arabia.

\section{Climatic Conditions of Taif Area}

The area of study is located at the western of Saudi Arabia (see Figure 4). In general, Taif climate is warm desert for most climatic classification and it is considered as dry climate because rainfall is less than $10 \mathrm{inch}$. Also, the humidity is less than $40 \%$ for most months. The temperature history of Taif for 7 days is shown in Figure 5. Also, the dew point for these seven days is demonstrated in Figure 6.

The application of desiccant system for water recovery from air requires night absorption of water vapor from atmospheric air and solar regeneration at day time. In the climatic conditions of Taif area, the most humid zone must be selected for this application. Generally, the weather is dry. It can be observed that, the dew point in most of these days in October ranges from -2 to 6 C. On the other hand, Weather conditions for Al-Hada shows that the dew point is $22 \mathrm{C}$ for this period and the relative humidity is about $94 \%$ which means that the conditions of Al-Hada is the most suitable for application of the desiccant system to collect water.

\section{Solar Radiation Model}

An important parameter affecting the performance of the desiccant collector system is the radiation intensity in the location, where such system is applied. The system is powered by the total radiation incident on a tilted surface. In this study a simplified model for evaluating the solar radiation on a tilted surface will be applied.

The total radiation incident on a tilted surface could be evaluated in terms of the location, day of the year and time of the day. The total perceived solar radiation can be estimated by the following relationship [11]:

$$
I_{t}=R_{B} I_{B}+C I_{B n}\left(\frac{1+\cos s}{2}\right)+\left(I_{B}+I_{d}\right) \rho_{g}\left(\frac{1-\cos s}{2}\right)
$$




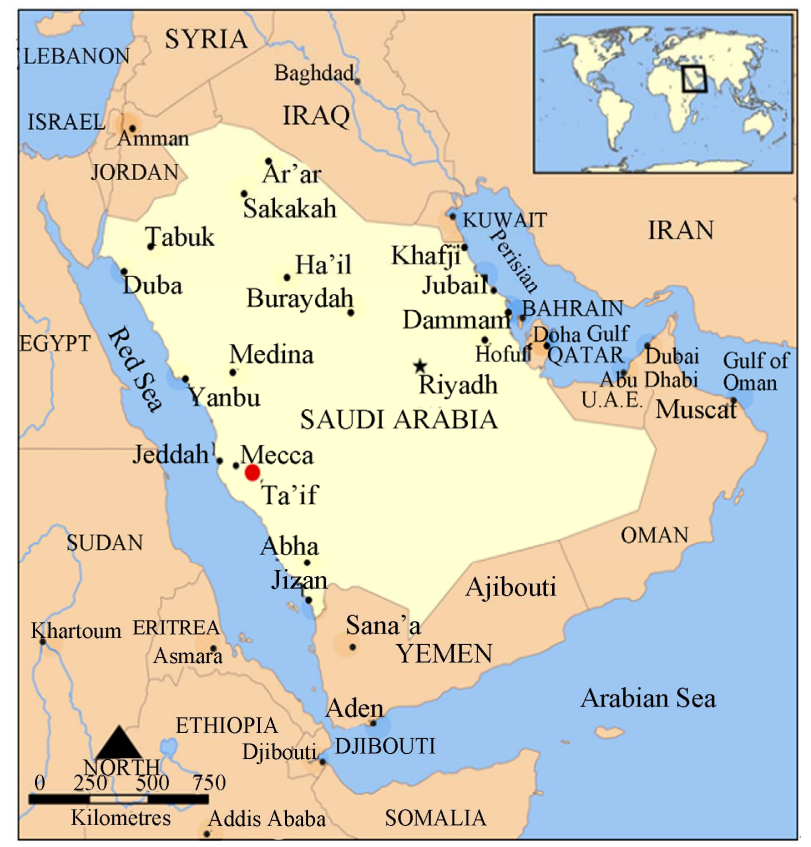

Figure 4. Map of KSA showing the location of Taif.

where, $\left[I_{B}\right.$ is beam radiation on a horizontal surface, $R_{B}$ is beam radiation tilt factor, $I_{B n}$ is beam radiation at normal incidence, $\mathrm{W} / \mathrm{m}^{2}, I_{d}$ is the diffuse sky radiation, $\mathrm{W} / \mathrm{m}^{2}, \mathrm{C}$ is diffuse radiation factor, $S$ is the surface tilt angle, $\rho_{g}$ is solar reflectance of the Earth's surface. The three terms in the above equation represent the direct, diffuse, and reflected components, respectively.

The terrestrial beam radiation within the atmosphere and on the earth's surface on a typical clear day is calculated using the following relation:

$$
I_{B n}=A \exp \left(\frac{-B}{\sin \alpha}\right)
$$

where, A is an empirically determined constant which represent the apparent solar radiation at air mass zero, $\mathrm{W} / \mathrm{m}^{2}, \mathrm{~B}$ is an apparent atmospheric extinction coefficient and $[\alpha$ is the solar altitude angle. The altitude angle $\alpha$ can be evaluated from the following expression:

$$
\sin \alpha=\sin L \sin \delta+\cos L \cos \delta \cos h
$$

where $L, \delta$ and $h$ are the latitude, declination and hour angles, respectively. The declination angle $\delta$ can be calculated as a function of the day number, $n$ as:

$$
\left[\delta=23.45 \sin \left[\frac{360}{365}(284+n)\right]\right.
$$

The hour angle is defined by:

$$
h= \pm \frac{1}{4}(\text { number of min from local solar noon })
$$

where the value of $h$ is assumed positive in the after noon period.

In Equation (1), the diffuse solar radiation is estimated from:

$$
I_{d}=C F_{s s} I_{B n}
$$

where, Fss $=0.5(1+\cos s)$ is the angle factor between the surface and the sky and $S$ is the tilt angle of the solar collector. The beam radiation tilt factor $R_{B}$ is defined by

$$
R_{B}=\frac{I_{B t}}{I_{B}}=\frac{\cos i}{\cos Z}
$$

where $I_{B t}, I_{B}$ are the beam radiation on a tilted surface and on the horizontal surface, respectively. The incidence angle, $i$, and zenith angle $z$ are calculated from the following expressions,

$$
\begin{gathered}
\cos i=\sin (L-s) \sin \delta+\cos (L-s) \cos \delta \cosh \\
\cos z=\sin \alpha
\end{gathered}
$$

The day length, D, which is the period from sunrise to sunset, can be evaluated from,

$$
D=\frac{2}{15} \cos ^{-1}(-\tan L \tan \delta)
$$

\section{Experimental Study}

The aim of the experimental work is to evaluate the performance of the system in the climatic conditions of Taif city, Saudi Arabia, with application of calcium chloride $(\mathrm{CaCl} 2)$, which is the most available and cheap absorbent, as the working desiccant. In the experimental part of this study, a desiccant solar collector system has been designed and installed in the thermodynamics Lab., Faculty of Engineering, Taif University. The desiccant/solar collector system comprises a flat plate solar collector in which a sandy bed impregnated with calcium chloride is located. The solution/sand mixing ratio is selected such that dropping of liquid from the bed at the end of absorption must be avoided. In the present study, each $\mathrm{kg}$ of sand is mixed with $0.15 \mathrm{~kg}$ of solution. To design an operating system, design data must be carefully selected considering the ambient conditions and the thermophysical properties of the absorbent. Some preliminary experiments were carried out to obtain the average value of the most suitable desiccant concentration. As the system absorbs water from atmospheric air at night period, solution concentration at the end of absorption is mainly dependent on the ambient conditions (temperature and humidity) Therefore, average ambient temperature and humidity at night are measured in the zone of Taif city, then the most suitable concentration of desiccant is determined. The bed thickness is selected such that when solution reaches the saturation condition, corresponding 


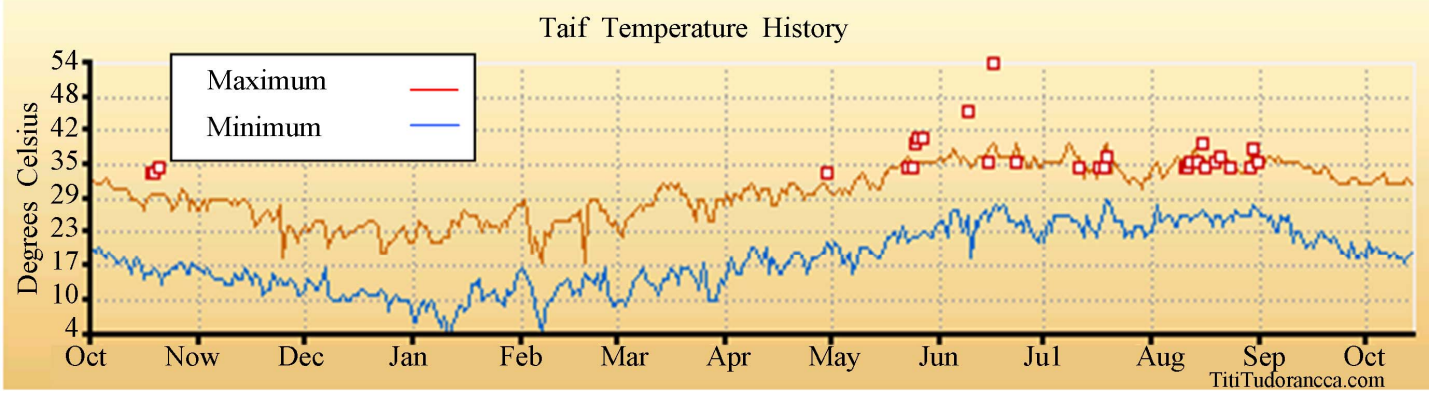

Figure 5. Temperature history for Taif.

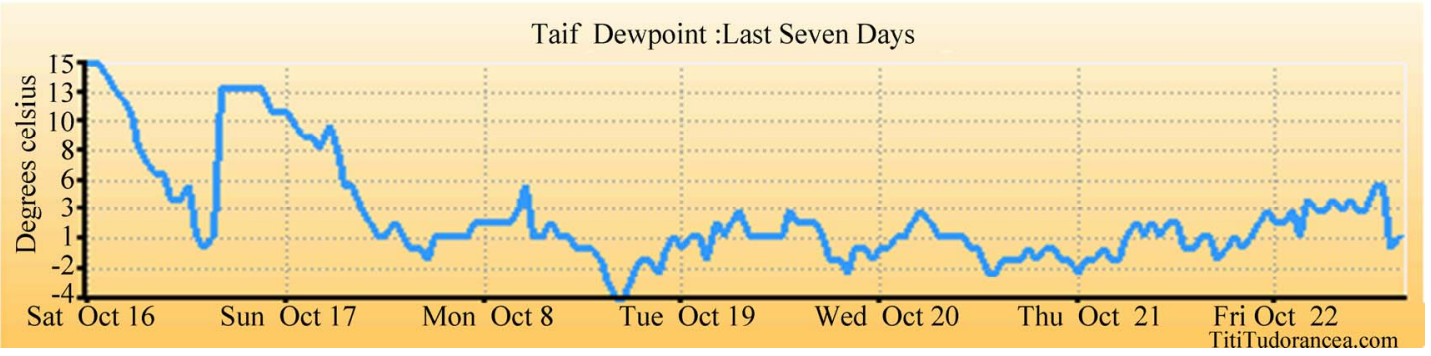

Figure 6. Dew point temperature for Taif for seven days.

to vapor pressure in the ambient atmosphere, it must be able to carry all the mass of weak solution at the end of the absorption process, i.e. falling of liquid drops from the bed must be avoided.

A general view of the experimental apparatus is illustrated in Figure 7. It consists mainly of a box having cross section of $(0.5 \mathrm{~m} \times 1.0 \mathrm{~m})$ and $0.3 \mathrm{~m}$ height. A glass cover which has a cross sectional area of $0.5 \mathrm{~m}^{2}$ and $3 \mathrm{~mm}$ thickness forms the apparatus upper side As shown in Figure 7. One of the four sides of the box functions as removable cover, which can be removed to allow the absorption at night and remove the bed from the box. The box is insulated by high density foam of $0.03 \mathrm{~m}$ thickness. During the experimental tests, the solar collector is installed at an angle of about $20^{\circ}$ to the horizontal, which is nearly the latitude angle of the location. At daytime, the bed absorbs the incident solar radiation and consequently the bed temperature increases, as a result the vapor pressure of the solution on the bed surface increases and vapor pressure difference between the bed surface and glass cover is created. At this moment, evaporation of moisture from the bed is carried out with subsequent condensation on the glass surface. The drops of condensate are collected and led away from the system through specially designed channel. Evaporation and condensation continue until the vapor pressure on the bed surface is equal to that on the glass surface. At the end of the day the removable side of the box is opened and the bed is allowed to cool until the vapor pressure on its surface decreases to a value lower than that of the ambient air. Temperatures at different points in the system are recorded using k-type thermocouples, which are connected to a digital thermometer of $0.1^{\circ} \mathrm{C}$ resolution. Bed, glass surface and ambient temperatures are recorded during the operation period. Rubber hose connects the water exit point from the solar collector to a graduated glass flask (see Figure 7).

\section{Analysis of Experimental Data}

Vapor pressure on the bed surface can be calculated as a

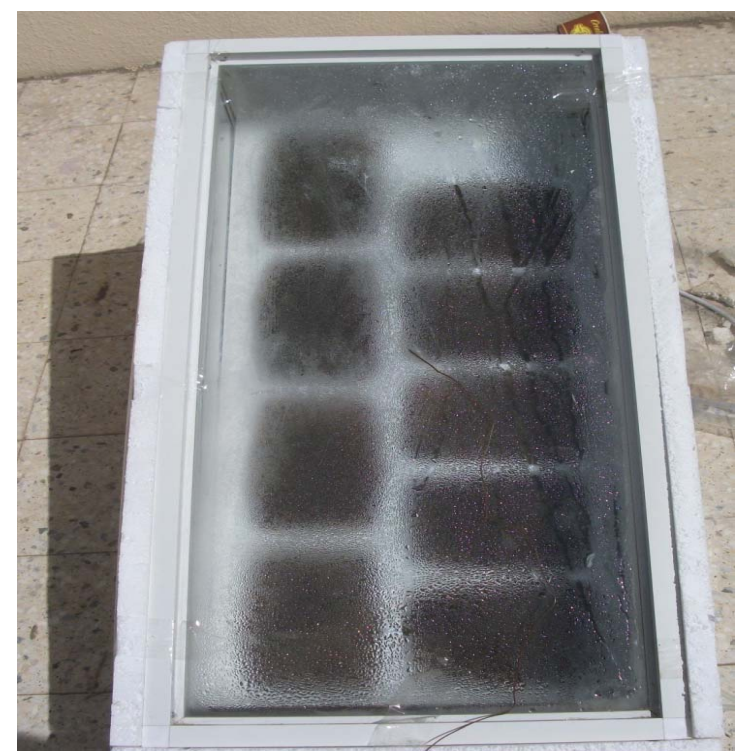

Figure 7. View of the experimental unit. 
function of solution temperature within temperature range from $10^{\circ} \mathrm{C}$ to $65^{\circ} \mathrm{C}$ and concentration range from $20 \%$ to $50 \%$ according to the following Equations (1):

$$
\ln \left(p_{b}\right)=A(x)-\frac{B(x)}{t_{b}+111.96}
$$

where $\mathrm{p}_{\mathrm{b}}$ is in $\mathrm{mm} \mathrm{Hg}, \mathrm{t}_{\mathrm{b}}$ in ${ }^{\circ} \mathrm{C}, \mathrm{A}(\mathrm{x})$ and $\mathrm{B}(\mathrm{x})$ are regression dependent parameters, which can be expressed as a linear function of concentration according to the following relations:

$$
\begin{aligned}
& A(x)=a_{0}+a_{1} x \\
& B(x)=b_{0}+b_{1} x
\end{aligned}
$$

where $a_{0}=10.0624, a_{1}=4.4674, b_{0}=739.828$ and $b_{1}=1450.96$.

During regeneration process the bed temperatures increases to values of about $100^{\circ} \mathrm{C}$, therefore, an expression for deriving the vapor pressure of solution for temperature range from 60 to $100^{\circ} \mathrm{C}$ is developed in the following form:

$$
\ln \left(p_{b}\right)=A-\frac{B(x)}{\left(t_{b}+273\right)}
$$

where $\mathrm{A}$ and $\mathrm{B}$ are regression constants. values of $\mathrm{A}, \mathrm{B}$ and their associated concentration are given in [15].

The average bed concentration at the end of a certain time interval $\Delta \tau$ can be calculated from the following equations:

$$
\begin{gathered}
M_{f}=M_{i}-P \times \Delta \tau \\
M_{f} X_{f}=M_{i} X_{i}=\text { const }
\end{gathered}
$$

where subscripts $f i$ refers to the final and initial values of mass $\mathrm{M}$, and concentration, $\mathrm{X}$.

Daily efficiency, $\eta$ of the system can be defined as:

$$
\eta=\frac{\sum q_{e}}{\sum H}
$$

where $\Sigma$ qe is the total heat of evaporation of water and $\Sigma \mathrm{H}$ is the total daily incident radiation.

\section{Results and Discussion}

Beam radiations at normal incidence as well as total radiation on the collector surface are plotted with time for the day and location of the experimental tests as shown in Figure 8. The accumulated solar radiation on the collector surface is evaluated by integration of the hourly values of total radiation and plotted in Figure 9. Typical results of hourly variation of ambient, glass surface and bed temperatures are presented graphically in Figure 10. It can be noted that the temperature difference between glass surface and bed increases gradually with time. This temperature difference has a significant effect on the mass transfer potential. However, this effect is limited by

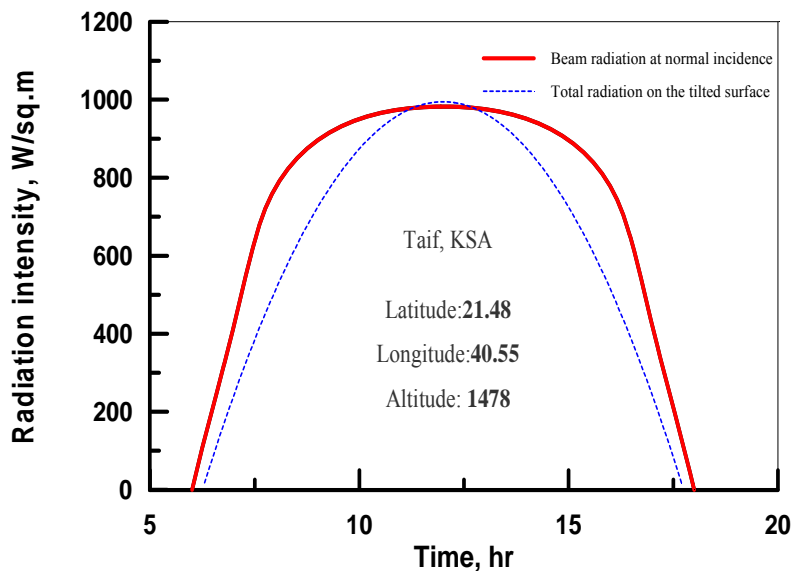

Figure 8. Beam radiation and total radiation at normal incidence.

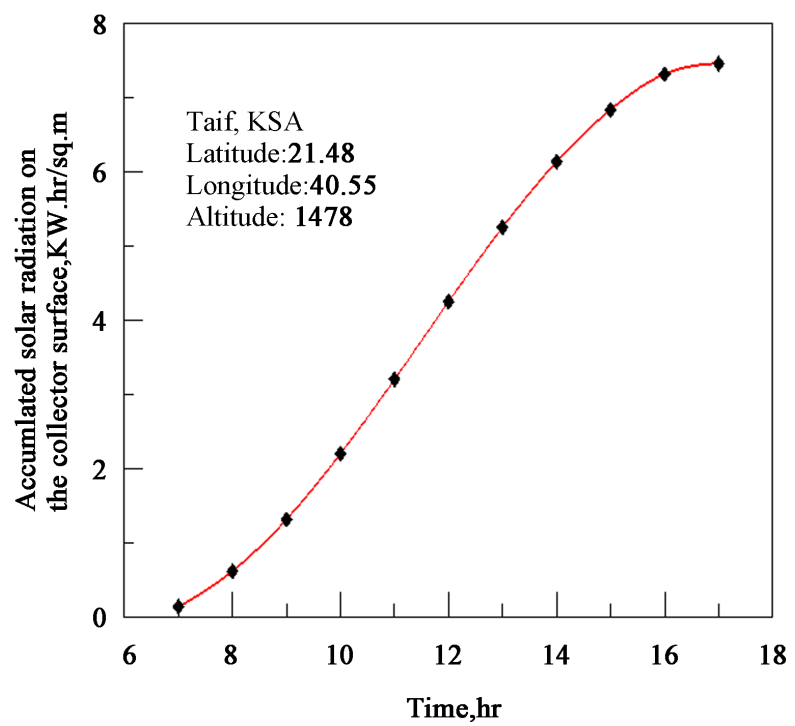

Figure 9. Accumulated solar radiation on the collector surface versus time.

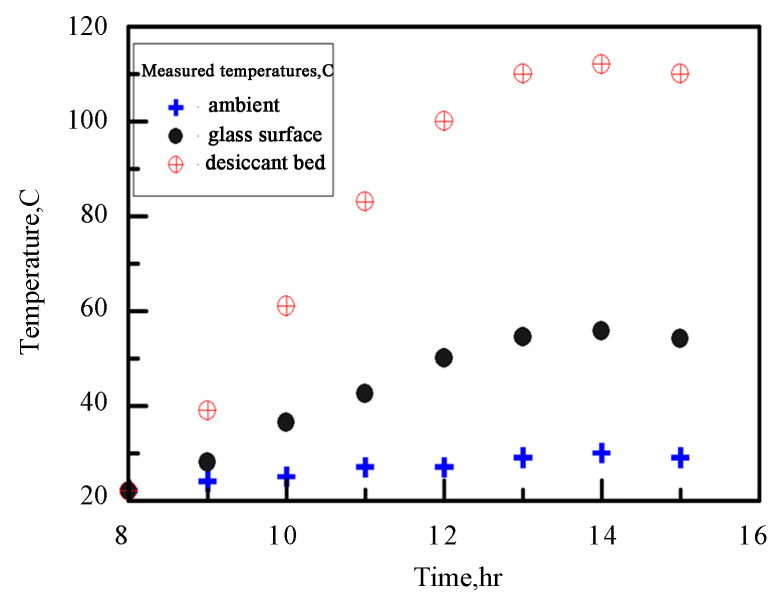

Figure 10. Hourly variation of ambient, glass surface and bed temperatures. 
the solution concentration, which increases with water evaporation from the desiccant. A maximum bed temperature of $112 \mathrm{C}$ is recorded at $2 \mathrm{pm}$. The maximum temperature difference between bed and glass surface is also recorded at $2 \mathrm{pm}$. From the analysis of experimental measurements, it is found that solution concentration increases from $30 \%$ to about $44 \%$ at the end of regeneration process. Also, an average daily efficiency of about $22 \%$ could be attained for the specified operating conditions. From the data and visual observation it can be stated that water condensation stops nearly at the period from 2-3 p.m. This means that the solution concentration increases such that the heating temperature cannot build the required potential for mass transfer from the bed to the glass surface during this period of operation. The daily-evaporated mass of water is evaluated from the difference of masses of the bed, where the mass of the bed is measured at the end of absorption and regeneration respectively. Evaluation of the mass of lost water vapor due to leakage is important, where the apparent conditions of such systems show proper sealing but, in most cases, leakage cannot be easily avoided. Therefore, perfect sealing of this system as with as the solar still is extremely important.

Relative humidity and humidity ratio of ambient air for Taif city and Al-Hada region are plotted against time at night for two different seasons in the year as shown in Figures 11 and 12 respectively. Applying equations from 11 to 14 , the equilibrium concentration of absorbing solution corresponding to the recorded data for Taif city and Al-Hada region can be evaluated. It can be found that the climate of Taif is dry compared with that of Al-Hada region and the equilibrium concentration for the two regions is different. For Al-Hada region, calcium chloride can absorb water from air at night periods in October up to a concentration of about $30 \%$.

\section{Conclusions}

Desiccant/collector solar regenerator has been designed, installed and experimentally tested at Taif area, Saudi Arabia. Calcium chloride solution has been applied as the working desiccant. From the experimental measurements and data analysis, the following conclusions can be drawn:

The solar powered desiccant system which uses sandy bed can be successfully applied to recover water from air and an average amount of 1.0 liter of fresh water can be recovered per square meter, when the solution concentration at equilibrium with the night conditions is about $30 \%$.

It is found that the system is more efficient when operating at Al-Hada region where the dew point is higher compared with the city of Taif.

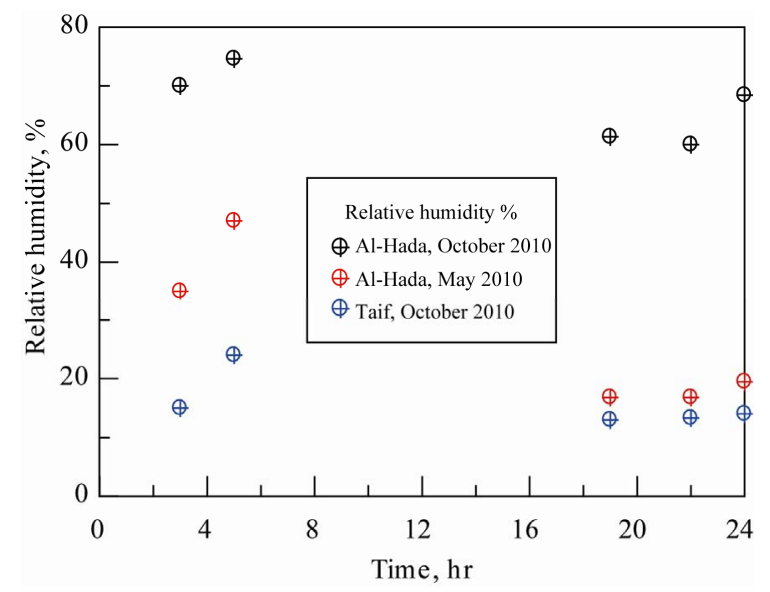

Figure 11. Recorded values of relative humidity for Taif City Al-Hada region.

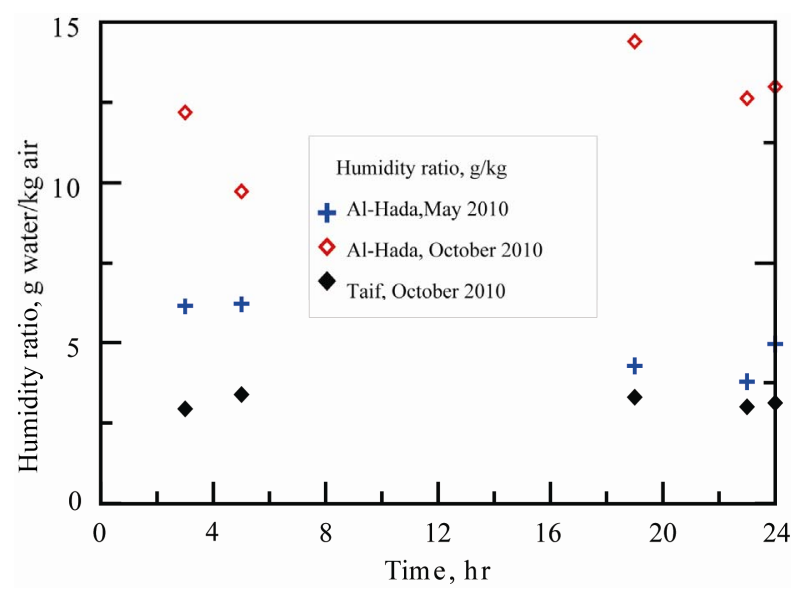

Figure 12. Humidity ratio for Al-Hada and taif city at different seasons.

The season of operation of such system determines the operating concentration of the solution. Therefore, it is recommended to use solution with higher concentration for dry seasons and areas.

\section{Acknowledgements}

This study is supported by Taif University under a contract NO. 431-649. The University is highly acknowledged for the financial support.

\section{REFERENCES}

[1] A. M. Hamed, "Absorption-Regeneration Cycle for Production of Water from Air-theoretical Approach," Re newable Energy, Vol. 19, No. 4, 2000, pp. 625-635. doi:10.1016/S0960-1481(99)00068-3

[2] V. E. Obrezkova, "Hydro-energy," Energoatomezdat, Moscow, 1988.

[3] F. M. Al Zawad, "Impacts of Climate Change on Water Resources in Saudi Arabia," The 3rd International Con- 
ference on Water Resources and Arid Environments and the 1st Arab Water Forum, 16-19 November 2008.

[4] M. A. Al-Sohlawi, "Seawater Desalination in Saudi Arabia: Economic Review and Demand Projections," Desalination, Vol. 123, No. 2-3, 1999, pp. 143-147. doi:10.1016/S0011-9164(99)00067-3

[5] M. S. Aljohani, "Nuclear Desalination Competitiveness in the Western Region of the Kingdom of Saudi Arabia," Desalination, Vol. 164, No. 3, 2004, pp. 213-223. doi:10.1016/S0011-9164(04)00190-0

[6] V. V. Tygarinov, "An Equipment for Collecting Water from Air,” Patent No. 69751, Russia, 1947.

[7] M. Kobayashi, "A Method of Obtaining Water in Arid Land," Solar Energy, Vol. 7, 1963, pp. 93-99. doi:10.1016/0038-092X(63)90034-3

[8] I. EL-Sharkawy, "Production of Water by Extraction of Atmospheric Moisture Using Solar Energy," M.Sc. Thesis, Mansoura University, Egypt, 2000.

[9] A. Sultan, "Absorption/Regeneration Non-Conventional System for Water Extraction from Atmospheric Air," Renewable Energy, Vol. 29, No. 9, 2004, pp. 1515-1535. doi:10.1016/S0960-1481(03)00020-X

[10] R. C. Hall, "Production of Water from the Atmosphere by Absorption with Subsequent Recovery in a Solar Still," Solar Energy, Vol. 10, No. 1, 1966, pp. 42-45. doi:10.1016/0038-092X(66)90071-5

[11] H. Sofrata, "Non-conventional System for Water Collection," Proceedings of Solar Desalination Workshop, SERI, Denver, Colorado, 1981, pp. 71-87.

[12] Y. Alayli, N. E. Hadji and J. Leblond "A New Process for the Extraction of Water from Air," Desalination, Vol. 67, pp. 227-229.

[13] A. M. Hamed, "Non-Conventional Method for Collecting Water from Air Using Solar Energy," PhD Thesis, Russian Academy of Science, 1993.

[14] H. I. Abualhamayel, P. Gandhidasan, "A Method of Obtaining Fresh Water from the Humid Atmosphere," Desalination, Vol. 113, 1997, pp. 5 1-63.

[15] H. E. Gad, A. M. Hamed and I. EL-Sharkawy, “Application of a Solar Desiccant/Collector System for Water Recovery from Atmospheric Air," Renewable Energy, Vol. 22, No. 4, 2001, pp. 451-556. doi:10.1016/S0960-1481(00)00112-9

[16] A. M. Hamed, "Experimental Investigation on the Natural Absorption on the Surface of Sandy Layer Impregnated with Liquid Desiccant," Renewable Energy, Vol. 28, 2003, pp. 1587-1596. doi:10.1016/S0960-1481(03)00005-3

[17] A. E. Kabeel, "Application of Sandy Bed Solar Collector System for Water Extraction from Air," International Journal of Energy Research, Vol. 30, 2006, pp. 381-394. doi:10.1002/er.1155

[18] U. Bardi, "Fresh Water Production by Means of Solar
Concentration: the AQUASOLIS Project," Desalination, Vol. 220, No. 1-3, 2008, pp. 588-591. doi:10.1016/j.desal.2007.04.059

[19] N. P. Clarke and C. Calif, "Atmospheric Water Extractor and Method," United States Patent 5233843, 10 August 1993.

[20] A. E. Kabeel, "Water Production from Air Using Multi-Shelves Solar Glass Pyramid System," Renewable Energy, Vol. 32, No. 1, 2007, pp. 157-72. doi:10.1016/j.renene.2006.01.015

[21] YU. I. aristov, M. M. Tokarev, L. G. Gordeeva, V. N. Snytnikov and V. N. Parmon, "New Composite Sorbents for Solar-driven Technology of Fresh Water Production from the Atmosphere," Solar Energy, Vol. 66, No. 2, 1999, pp. 165-168. doi:10.1016/S0038-092X(98)00110-8

[22] G. Ji, R. Z. Wang and L. X. Li, "New Composite Adsorbent for Solar-Driven Fresh Water Production from the Atmosphere," Desalination, Vol. 212, No. 1-3, 2007, pp. 176-182. doi:10.1016/j.desal.2006.10.008

[23] A. M. Hamed, "Parametric Study of the AdsorptionDesorption System Producing Water from Ambient Air," International Journal of Renewable Energy Engineering, Vol. 2, 2000, pp. 244-252.

[24] A. Khalil, "Dehumidifiation of Atmospheric Air as a Potential Source of Fresh Water in the Uae," Desalination, Vol. 93, 1993, pp. 587-596. doi:10.1016/0011-9164(93)80133-8

[25] B. A. Habeebullah, "Potential Use of Evaporator Coils For Water Extraction in Hot and Humid Areas," Desalination, Vol. 237, 2009, pp. 330-345. doi:10.1016/j.desal.2008.01.025

[26] A. F. G. Jacobs, B. G. Heusinkveld and S. M. Berkowicz, "Passive Dew Collection in a Grassland Area," The Netherlands Atmospheric Research, Vol. 87, No. 3-4, 2008, pp. 377-385. doi:10.1016/j.atmosres.2007.06.007

[27] D. Beysensa, O. Clusc, M. Miletac, I. Milimoukc, M. Musellic and V. S. Nikolayeva, "Collecting Dew as a Water Source on Small Islands: the Dew Equipment for Water Project in Bis ${ }^{-E v o ~(C r o a t i a), " ~ E n e r g y, ~ V o l . ~ 32, ~ N o . ~}$ 6, 2007, pp. 1032-1037. doi:10.1016/j.energy.2006.09.021

[28] P. Gandhidasan and H.I. Abualhamayel, "Modeling and Testing of a Dew Collection System," Desalination, Vol. 180, 2005, pp. 47-51. doi:10.1016/j.desal.2004.11.085

[29] G. A. Al-hassan, "Fog Water Collection Evaluation in Asir Region-Saudi Arabia," Water Resources Management, Vol. 23, No. 13, 2009, pp. 2805-2813. doi:10.1007/s11269-009-9410-9

[30] R. V. Wahlgren, "Atmospheric Water Vapour Processor Designs for Potable Water Production: a Review," Water Resources Management, Vol. 35, No. 1, 2001, pp 1-22. 